\title{
The influence of culture on maternal soothing behaviours and infant pain expression in the immunization context
}

\author{
Jillian Vinall $B A^{1}$, Rebecca Pillai Riddell $\mathrm{PhD}^{1,2}$, Saul Greenberg $\mathrm{MD}^{3,4}$
}

\begin{abstract}
J Vinall, R Pillai Riddell, S Greenberg. The influence of culture on maternal soothing behaviours and infant pain expression in the immunization context. Pain Res Manage 2011;16(4):234-238.
\end{abstract}

OBJECTIVE: To investigate how maternal culture (ie, individualist versus collectivist) influences soothing techniques and infant distress. METHODS: Archival data were analyzed using a subsample of 80 motherinfant dyads selected from a larger database of infant pain expression. RESULTS: Mothers belonging to the individualist group used more affection behaviours when attempting to regulate their infants' distress. No differences were observed in mothers' touching, holding, rocking, vocalizing, caregiving or distracting their infants. Mothers' culture did not appear to be related to the level of distress expressed by their infants.

CONCLUSIONS: These results suggest that the similarities in soothing and infant pain expression between individualist and collectivist cultures are more prominent than their differences.

Key Words: Acculturation; Culture; Mother-infant interactions; Pain; Soothing

\section{L'influence de la culture sur les comportements d'apaisement de la mère et l'expression de la douleur par les nourrissons dans le contexte de la vaccination}

OBJECTIF : Explorer en quoi la culture de la mère (individualiste ou collective) influe sur les techniques d'apaisement et la détresse des nourrissons.

MÉTHODOLOGIE : Les chercheurs ont analysé les données archivistiques au moyen d'un sous-échantillon de 80 dyades mèrenourrisson sélectionnées dans une plus grande base de données d'expressions de la douleur chez les nourrissons.

RÉSULTATS : Les mères qui appartiennent au groupe individualiste utilisent davantage de comportements d'affection lorsqu'elles tentent de régulariser la détresse de leur enfant. Les chercheurs n'ont remarqué aucune différence pour ce qui est de toucher, de tenir, de bercer, de faire des vocalises, de distraire leur nourrisson ou de lui administrer des soins. La culture de la mère ne semblait pas être liée au taux de détresse exprimé par leur nourrisson.

CONCLUSIONS : Ces résultats indiquent qu'il y a davantage de similarités que de différences entre la culture individualiste et la culture collective dans l'expression du réconfort et de la douleur par les nourrissons.
$\mathrm{T}$ he Sociocommunication Model of Infant Pain posited by Craig and Pillai Riddell (1) examines the reciprocity of influence between the infant in pain and his/her caregiver, in the larger context of social factors. Culture is one example of these social factors and it is the broadest sphere of influence in the Sociocommunication Model. Cultural factors are postulated to have important implications for infant pain expression and caregiver management strategies. Per capita, Canada accepts more immigrants than any other country (2). Thus, understanding the impact of cultural identity on caregiver soothing behaviour and infant distress is an important realm of study. The purpose of the present study was to explore the impact of maternal culture on soothing behaviours and infant cry duration in an immunization setting. However, before proceeding, it is crucial to establish working definitions.

Culture is a learned belief system, in which values are affiliated with, modelled and upheld by group members (3). However, in discussing cultural groups, one must be aware of the diversity of individuals within that group. Contributing to this intragroup variability is the process of acculturation. Acculturation, as defined by Redfield, Linton and Herskovits, refers to the degree of change in a person's schema that is a result of having contact with different cultural origins (4). A useful operationalization of this construct is Beery's bidimensional perspective of culture: a person has both a personal cultural background, reflecting their family (heritage culture), and a larger cultural context that they live within (mainstream culture) (5). Thus, participants recruited from Canadian immunization clinics represent the same mainstream culture (ie, North American); however, they may differ in their heritage culture (eg, Muslim, Irish, etc). This emphasizes the idea that simply knowing a Canadian subjects' heritage culture is not enough. By understanding a participant's strength of affiliation with both their heritage and mainstream cultures, a researcher may be able to obtain more meaningful data pertaining to a participant's cultural context.

Social expectations driven by the values underlying one's culture can explicate one theoretical mechanism by which a culture might influence behaviour (ie, soothing/distress). In their cross-national study using factorial analysis, Hofestede and Bond (6) were able to demonstrate cultural differentiation and classification of cultural groups based on four value dimensions: power distance, uncertainty avoidance, individualism versus collectivism, and masculinity versus femininity. One of the most widely accepted dimensions relates to individualism versus collectivism. While complete agreement regarding the definition of these concepts is elusive (7), many researchers have based their definitions on how individuals integrate themselves into groups (7-9). Individualists are regarded as independent and self-reliant, whereas collectivists are seen as more socially interdependent and family oriented (8-12). Examples of individualist cultures are western Europe, North America and Australia, while collectivist cultures have roots in Asia, Africa and South America (8). Furthermore, evidence suggests that values stemming from these two types of cultures are fairly stable across time and contexts (13). Therefore, individualism versus collectivism was the classification system chosen to dichotomize participants in the present study because we believed that cultural beliefs associated with this dichotomy may subsume differences in caregiver soothing behaviour and subsequent infant distress reactivity.

Caregivers from individualist and collectivist cultures have been shown to have differential expectations of appropriate displays of affection $(14,15)$. Due to these expectations, they may respond differently

${ }^{1}$ Department of Psychology, York University; ${ }^{2}$ Department of Psychiatry, Research; ${ }^{3}$ Department of Pediatrics, The Hospital for Sick Children; ${ }^{4}$ Department of Pediatrics, University of Toronto, Toronto, Ontario

Correspondence: Ms Jillian Vinall, Developmental Neurosciences $\mathcal{E}$ Child Health, L408, 4480 Oak Street, Vancouver, British Columbia

V6H 3V4. Telephone 604-875-2000, e-mail jvinall@cw.bc.ca 


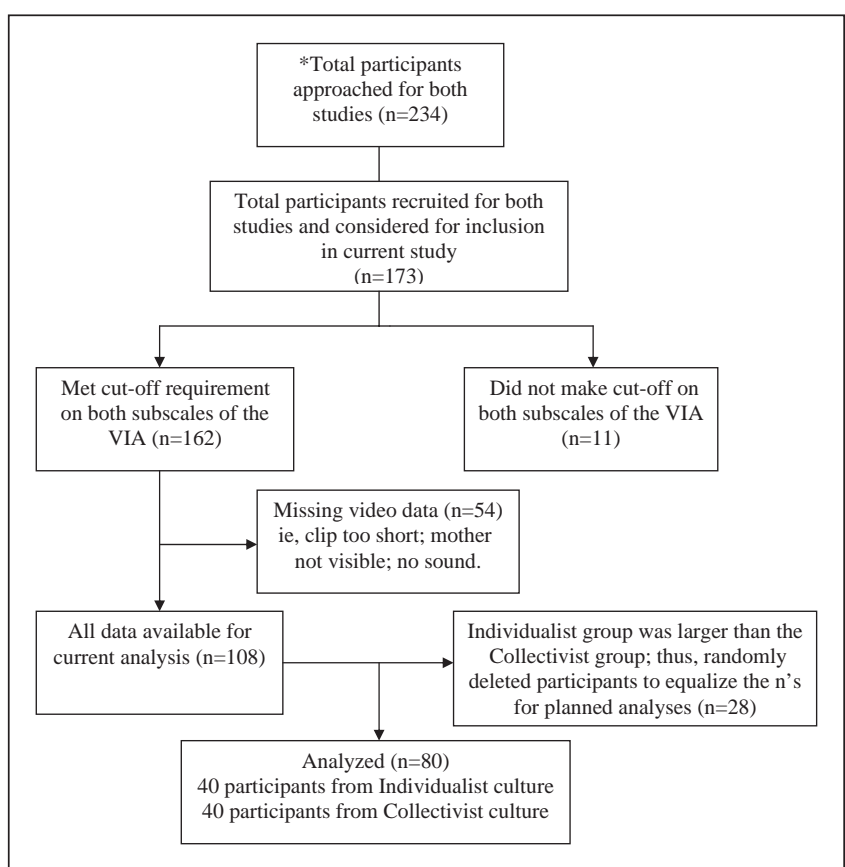

Figure 1) Participation flow chart. *Recruitment rates for the original studies: 93\% (Pillai Riddell et al [21]; lower risk community sample) and 60\% (Din et al [22]; higher risk community sample). VIA Vancouver Index of Acculturation

to their infants (16). These behavioural differences may explain some of the variation in levels of distress such as the greater level of distress expressed by infants from individualist cultures $(17-20)$. While these studies have found that infants from individualist cultures demonstrate greater emotional expressivity than infants from collectivist cultures $(14,17-20)$ and that differences do exist in how parents from individualist versus collectivist cultures react to their children, none of these studies controlled for the level of acculturation in a pain context. Rather, they simply depended on a participant's self-report of a heritage culture, without determining whether that participant actually identified with that culture. Thus, there is a wide gap in the literature pertaining to culture/acculturation and its effects on pediatric pain. Taking a step forward from previous research, a level of acculturation to both mainstream and reported heritage culture was ensured. The present study explored how 'culturally integrated' mothers (ie, they not only reported what their heritage culture was, but also were classified as being strongly influenced by both their heritage and mainstream cultures) soothe their children based on whether their heritage culture is collectivist or individualist, and whether there is a relationship between cultural identity and infants' distress.

\section{STUDY OVERVIEW}

The current study explored whether maternal heritage culture (ie, individualist versus collectivist) impacts soothing behaviours following immunization when mothers' acculturation status is culturally integrated. The study addressed two main questions:

- When mothers report being strongly influenced by both their heritage and mainstream cultures, does a mother's heritage culture (ie, individualist versus collectivist) impact which techniques she uses to soothe her infant when in distress?

- When mothers report being strongly influenced by both their heritage and mainstream cultures, does a mother's heritage culture (ie, individualist versus collectivist) relate to the level of distress expressed by her infant?

In light of the research previously reviewed, it was hypothesized that differences would be evident in the type and frequency of soothing behaviours exhibited by collectivist and individualist cultures.
TABLE 1

Highest level of education for individualist and collectivist mothers

\begin{tabular}{lcc}
\hline Education & Individualist & Collectivist \\
\hline Graduate school & $20(50.0)$ & $13(32.5)$ \\
University graduate & $11(27.5)$ & $17(42.5)$ \\
Partial university & $2(5.0)$ & $3(7.5)$ \\
Trade school & $5(12.5)$ & $5(12.5)$ \\
Total & $38(95.0)$ & $38(95.0)$ \\
Unknown & $2(5.0)$ & $2(5.0)$ \\
\hline
\end{tabular}

Data presented as n (\%)

TABLE 2

Maternal self-reported heritage culture

\begin{tabular}{ll}
\hline Heritage culture & $\%$ \\
\hline North American & 20 \\
South American & 14 \\
Western European & 30 \\
Eastern European & 10 \\
Asian & 21 \\
African & 5 \\
\hline
\end{tabular}

Moreover, because caregivers from individualist and collectivist cultures interpret and subsequently respond to pain differently, we hypothesized that infants from individualist cultures would express greater distress compared with infants from collectivist cultures.

\section{Participants}

\section{METHODS}

The data used for the present study were archival $(21,22)$. These mother-infant dyads were a convenience sample from two pediatric clinics in midtown and northwest Toronto (Ontario). The inclusion criteria for the original database required that mothers were fluent in English and that they would be available for two parts of the study including the videotaped clinic interview and a subsequent telephone interview. Their infants were required to be between three and 20 months of age, and be healthy and full-term, with no suspected developmental delays or impairments, chronic illnesses or previous admittance to a neonatal intensive care unit. For the current study, dyads underwent an additional screening process to ensure that only mothers who had complete video data, complete interview data and had adequately endorsed the norms of their heritage and mainstream cultures on the Vancouver Index of Acculturation scale (4) were included (Figure 1).

Mothers: Eighty mothers were included in the study. They ranged from 20 to 42 years of age (mean [ \pm SD] age: individualists $32.85 \pm 3.89$ years; collectivists $32.37 \pm 4.75$ years). Mothers had an average of 1.66 children, and $80 \%$ of the mothers were married (34 individualists and 30 collectivists). Seventy-six per cent of mothers had a university education or higher (Table 1). Twenty-eight per cent of mothers were working, and 78\% had taken or were on a maternity leave (36 individualists and 36 collectivists). The mothers identified themselves as coming from a variety of cultures (Table 2). (An explanation of 'individualist versus collectivist' classifications is provided in the Measures section.)

Infants: The infants receiving immunization injections were between three and 20 months of age (mean 10.00 \pm 4.59 months). There were 40 males and 40 females. During their visit, infants could have received one or more of the following immunizations: diphtheria-tetanus-acellular pertussis, Haemophilus influenzae type B, pneumococcal conjugate vaccine, hepatitis $\mathrm{B}$ vaccine, meningococcal $\mathrm{C}$ conjugate, measles-mumps-rubella, varicella or inactivated poliovirus.

\section{Procedure}

The following procedure and analyses were approved by the York University Research Ethics Board and The Hospital for Sick Children Research Ethics Board (Toronto, Ontario). On an eligible mother's 
TABLE 3

Differences between individualist and collectivist cultures

\begin{tabular}{|c|c|}
\hline $\begin{array}{l}\text { Individualist* } \\
\text { (typically reflect western ideals) }\end{array}$ & $\begin{array}{l}\text { Collectivist }^{\dagger} \\
\text { (typically reflect eastern ideals) }\end{array}$ \\
\hline Independent & Socially interdependent \\
\hline Self-reliant & Connected \\
\hline Achievement orientated & Moderate/traditional \\
\hline Competitive & Cooperative \\
\hline Assertive & Obedient \\
\hline Pleasure seeking & Self-sacrificing \\
\hline Self-assured & Sensitive \\
\hline Direct & Self-controlled \\
\hline Self-interest & Equalitarian \\
\hline
\end{tabular}

${ }^{*}$ Examples: Western Europe, North America and Australia; ${ }^{\dagger}$ Examples: Asia, Africa and South America

arrival to the clinic, the receptionist gave her a flyer, which advertised the study. If participants were interested in the study, the research assistant (RA) approached them and provided a more thorough description. If participants agreed and met all the requirements, they were asked to sign two consent forms relating to participation and videotaping. Also, a telephone interview was scheduled within one to two weeks after the visit to the clinic. Sealed questionnaire packages were given, but were to remain sealed until the commencement of the telephone interview. All parents reported opening the envelope while speaking with the interviewer on the telephone. The immunization was videotaped to capture how the infant and mother interacted during the procedures. For the current study, the videotape was examined for $1 \mathrm{~min}$ following the injection (for both the infant pain expression and maternal soothing behaviours). Later, mothers were contacted for their scheduled follow-up telephone interview with a trained RA. These interviews lasted approximately $30 \mathrm{~min}$ to $45 \mathrm{~min}$. A demographic form and a measure of acculturation were among the questionnaires completed during the telephone interview.

\section{Equipment}

Two digital camcorders were used to record the clinic visit. One was set on a tripod and the other was held by the RA. These were used to capture mother-infant interactions. Videorecordings were transferred to DVDs and used for behavioural coding.

\footnotetext{
Measures

Demographics: Questions asked during the telephone interview pertained to the mother's age, marital status, highest level of education, number and ages of children, and whether she took a maternity leave. Acculturation: The Vancouver Index of Acculturation (4) is a 20 -item self-report measure that assesses a person's level of acculturation by examining factors such as values, social relationships and adherence to traditions. Participants responded to questions that related to how much they identified with norms and beliefs from both their self-reported heritage culture and mainstream North American culture. Thus, questions pertaining to both their identification with heritage and mainstream North American cultures were asked, and the test-taker was required to rate each item on a scale from 1 (strongly disagree) to 9 (strongly agree). Two subscales were derived (mainstream and heritage). The higher the score, the more that person identified with the culture in question. Examples of questions include, "I would be willing to marry a person from my heritage culture" and "I would be willing to marry a North American person". Using these scales, participants were selected based on 'strong identification' with their heritage and the mainstream North American culture (Figure 1). It was conservatively decided that participants needed to be more in agreement with the practices, values and beliefs of both cultures than in disagreement. Thus, an overall mean rating of at least 5 (out of 9) was required for participation. The internal consistency (alpha)
}

coefficients were found to be 0.91 to 0.92 for the heritage subscale and 0.85 to 0.89 for the mainstream subscale (4).

Division of heritage culture: First, participants were asked to selfreport their heritage culture by responding to the following prompt:

Many of these questions will refer to your heritage culture, meaning the culture that has influenced you most (other than North American culture). It may be the culture of your birth, the culture in which you have been raised, or another culture that forms part of your background. If there are several such cultures, pick the one that has influenced you most (eg, Irish, Chinese, Mexican, Black). If you do not feel that you have been influenced by any other culture, please try to identify a culture that may have had an impact on previous generations of your family. Your heritage culture (other than North American) is:

Then, after reviewing the literature (8-12,23-25), a list of criteria whereby a participant's self-reported heritage culture could be classified as either collectivist or individualist was created and used to sort the cultures (Table 3). An RA, who was blinded to the study hypotheses, used a priori criteria to independently reclassify $25 \%$ of the total sample. Inter-rater reliability was considered to be excellent, with $97.1 \%$ agreement.

Soothing behaviours: The Parental Regulatory Behavior Categories (26) is a reliable and valid coding system that enables a trained observer to count caregiver behaviours used to soothe their infants in an acute pain scenario. It was used to measure maternal soothing behaviours elicited during the $1 \mathrm{~min}$ following immunization. The measure includes 11 behaviours: affection, touching, holding, rocking, vocalizing, caretaking, distraction, feeding, presenting face, pacifying and other. They were totalled as frequency scores (ie, the number of $5 \mathrm{~s}$ epochs that the behaviour occurred within the time frame) resulting in a score from 0 to 12, which was treated as continuous. In the present study, four of the variables (presenting face, feeding, pacifying and other) were not analyzed due to rare occurrences. Each behaviour was scored and analyzed individually; thus, the omission of the four behaviours did not impact the validity or reliability of the other variables. The seven other variables (affection, touching, holding, rocking, vocalizing, caretaking and distracting) demonstrated inter-rater reliability (intraclass correlation scores ranged from 0.87 to 0.99 ).

Infant distress as a measure of time: To operationalize infant distress, length of cry was used. Cry was defined by a standardized measure - the Modified Behaviour Pain Scale (27). The duration of the cry was measured using a stopwatch beginning from immediately after the final needle and up to $1 \mathrm{~min}$ following injection. Twenty per cent of participants were double timed by a blinded RA to ensure reliability. Coders were in agreement $99.2 \%$ of the time.

\section{RESULTS}

The first analyses assessed whether self-reported maternal heritage culture impacted the techniques the mother used to soothe her infant when in distress. This was accomplished by conducting a Hotelling's $\mathrm{T}^{2}$ test followed by post hoc analyses. Second, an independent samples $t$ test was used to examine the relationship between self-reported maternal heritage culture and the level of distress expressed by their infant. Assumptions of normality (skewness and kurtosis), independence and equality of variances (Levene's [univariate] and Box's M [multivariate]) were tested and deemed to be satisfactory, although linear transformations (square root) were required for two of the variables (caregiving and distraction).

\section{Cultural variation in soothing techniques}

A Hotelling's $\mathrm{T}^{2}$ test, followed by a post hoc analysis, was conducted to examine whether maternal heritage culture (ie, individualist versus collectivist) impacted the techniques the mother used to soothe her infant when in distress. Due to the exploratory nature of these analyses, an alpha level of 0.10 was used for the overall Hotelling's $\mathrm{T}^{2}$ test. The 
TABLE 4

Variations in soothing behaviours for individualist $(I)$ and collectivist (C) mothers

\begin{tabular}{lccrc}
\hline \multirow{2}{*}{$\begin{array}{l}\text { Soothing } \\
\text { behaviour }\end{array}$} & \multicolumn{2}{c}{ Post hoc $\boldsymbol{t}$ test, mean \pm SD } & & P \\
\cline { 2 - 4 } & $\mathbf{I}$ & $\mathbf{C}$ & $\boldsymbol{t}$ & $\mathbf{P}$ \\
\hline Affection & $3.28 \pm 2.49$ & $1.88 \pm 2.10$ & -2.72 & $0.01^{*}$ \\
Touching & $2.28 \pm 2.11$ & $2.90 \pm 2.63$ & 1.17 & 0.25 \\
Holding & $4.24 \pm 3.13$ & $3.70 \pm 3.47$ & -0.74 & 0.46 \\
Rocking & $4.40 \pm 3.36$ & $3.98 \pm 3.87$ & -0.52 & 0.60 \\
Vocalizing & $7.28 \pm 3.42$ & $6.58 \pm 3.27$ & -0.94 & 0.35 \\
Caretaking & $0.79 \pm 1.06$ & $0.61 \pm 0.89$ & -0.81 & 0.42 \\
Distraction & $0.59 \pm 0.83$ & $0.79 \pm 0.99$ & 0.96 & 0.34 \\
\hline
\end{tabular}

*Significant at the 0.01 level

overall Hotelling's $\mathrm{T}^{2}$ was significant at $\mathrm{P}<0.10\left(\mathrm{~T}^{2}=0.180, \mathrm{P}=0.090\right)$. Post hoc $t$ test analyses revealed that the affection subscale was significantly different between culture types $(t[78]=-2.716, \mathrm{P}=0.008)$ ( Table 4). Data indicated that mothers from individualist cultures exhibited more affection behaviours when attempting to regulate their infants' distress.

\section{Cultural variation in infant distress}

The final analysis examined whether infants of mothers from individualist cultures expressed different levels of distress than infants of mothers from collectivist cultures (Table 5). An independent samples $t$ test revealed nonsignificant results suggesting equal levels of infant distress $(t[78]=-0.264, \mathrm{P}=0.792)$.

\section{DISCUSSION}

The purpose of the present study was to conduct an exploratory analysis examining the relationships between cultural identity, maternal soothing behaviours and infant distress in a sample of participants who were deemed to strongly identify with both their heritage culture and their mainstream North American culture. It was hypothesized that the types of soothing behaviours used by collectivist and individualist cultures would differ due to their contrasting beliefs and norms. In addition, infants from individualist cultures were expected to express greater distress. Based on the results of the present study, only the first of these hypotheses was partially supported.

The results of the analyses revealed that mothers belonging to individualist cultures used more affection when attempting to regulate their infant's distress. Affection is associated with feelings of love and security, and is demonstrated by behaviours such as kissing, hugging, face-to-face contact or holding closely $(26,28)$. This finding was consistent with those of previous studies $(29,30)$. While investigating child-rearing patterns of Japanese and American families, Power et al (29) determined that mothers of Japanese (collectivist) children self-reported as being less nurturing than mothers of American children. Similarly, in their longitudinal study (two months, 2.5 years and six years), Caudill and Schooler (30) observed greater levels of affectionate behaviour by the mothers of American (individualist) children versus the mothers of Japanese (collectivist) children. Similar to Caudill and Schooler (1973), Rudy et al (1999 [31]) found individualist cultures to be very responsive to their children's expressed emotional needs. In contrast, the parents belonging to collectivist cultures are more likely to promote self-regulatory behaviours. Therefore, our findings lend further support to this difference in affectionate behaviours.

Although there were differences in the level of affection displayed by mothers of individualist and collectivist cultures, it is noteworthy that similar amounts of touching, holding, rocking, vocalizing, caregiving and distracting were observed. These results are comparable with those previously found by Fogel et al (16) who, while studying maternal responding during a play session, found that individualist and collectivist cultures responded similarly to their infant's behaviour, with only a few minor differences (eg, more vocal responding from individualist mothers).
TABLE 5

Total time in distress for infants of mothers from collectivist and individualist groups

\begin{tabular}{lcc}
\hline Group affiliation & $\mathbf{n}$ & Time in distress (s), mean \pm SD \\
\hline Collectivist & 40 & $32.43 \pm 17.23$ \\
Individualist & 40 & $33.48 \pm 18.29$ \\
\hline
\end{tabular}

Given that representatives of individualist cultures have been shown to exhibit greater affect, we also hypothesized that infants of mothers from individualist cultures would demonstrate greater distress than the infants of mothers from collectivist cultures. However, the results were insignificant due to minimal mean differences between the groups (appoximately $1 \mathrm{~s}$ ). There was large within-group variability in crying for both groups of infants (SDs approaching $20 \mathrm{~s}$ ); thus, the between-group difference was not statistically significant.

Toronto is considered to be one of the most multicultural cities in the world (32); therefore, we were able to recruit a substantial sample of culturally integrated caregivers for the present study. By assessing their level of acculturation and ensuring that the participants identified with both their self-reported heritage culture and mainstream North American culture, the present study contributes to the pediatric pain literature by bringing a more nuanced understanding of the nature of hypothesized social dimensions such as culture (1).

Findings suggest that in the immediate immunization period, maternal cultural identity (individualist versus collectivist) does not impact the amount of most caregiver behaviours used nor the length of infant distress in a sample of culturally integrated dyads. Because the present study went beyond simply using participant reports of culture, this lack of differences gives strong evidence in favour of the adage that differences between individuals of a culture are greater than differences between cultural groups $(33,34)$. Although the mothers' cultural background appeared to be related to their tendency to use affectionate behaviours when soothing, the impact of this difference was not seen in levels of infant distress reactivity, suggesting that between-individual differences within a group are greater than between-group differences.

\section{Limitations and future directions}

The present study has several limitations. The duration of cry is not specific to pain and, thus, may be reflective of more general distress or negative affect. Some infants may have continued to cry or resumed crying after $1 \mathrm{~min}$ had passed; thus, future research could incorporate a longer time frame. Furthermore, given the sample size, our sample (while adequate for the analyses conducted) was not large enough to adequately explore covariates such as infant age, temperament and particular immunizations. Also, although the sample came from two very diverse neighbourhoods, the education level was high and may have had an independent effect on the level of maternal responding to infants. Therefore, generalizability across socioeconomic groups must be considered with caution (35). Finally, nationalities rather than individuals were classified within each of the two cultural groups (individualist versus collectivist). Individual participants within a cultural group (eg, two people who reported a heritage culture of Italian and a mainstream culture of Canadian) may have internalized different norms and beliefs from the same heritage culture. Future research in the area would benefit from individual assessments of a participant's alignment with key traits of individualism or collectivism that could relate to soothing behaviours.

ACKNOWLEDGEMENTS: The authors acknowledge the generous funding support of the Atkinson Junior Faculty Fund (York University) and the Canadian Institutes of Health Research (CIHR) for a New Investigator Award to Dr Pillai Riddell; and CIHR, CIHR's Strategic Initiative Pain in Child Health and the Child \& Family Research Institute for Masters Awards to Ms Vinall. 


\section{REFERENCES}

1. Craig KD, Pillai Riddell RR. Social influences, culture and ethnicity. In: Finley GA, McGrath PJ, eds. The Context of Pediatric Pain: Biology, Family Society and Culture. Seattle: IASP Press, 2003:159-82.

2. Canadian Psychological Association. Canada's multicultural society. $<$ http://www.cpa.ca $>$ (Accessed on May 19, 2009).

3. Tylor EB. Primitive Culture (Vol 1-2), 7th edn. New York: Brentano's, 1924:1.

4. Ryder AG, Alden LE, Paulhus DL. Is acculturation unidimensional or bidemensional? A head-to-head comparison in the prediction of personality, self-identity, and adjustment. J Pers Soc Psychol 2000;79:49-65.

5. Phinney JS, Devich-Navarro M. Variations in bicultural identification among African American and Mexican American adolescents. J Res Adolescence 1997;7:3-32.

6. Hofstede G, Bond MH. Hofstede's culture dimensions: An independent validation using Rokeach's Value Survey. J Cross Cult Psychol 1984;15:417-33.

7. Hooker J. Working Across Cultures. California: Stanford University Press, 2003:130-9.

8. Bornstein MH, Hahn C, Haynes MO, Belsky J, Azuma H, Kwak K. Maternal personality and parenting cognitions in cross-cultural perspectives. Int J Behav Dev 2007;31:193-209.

9. Brewer MB, Chen Y. Where (who.) are collectives in collectivism? Toward conceptual clarification of individualism and collectivism. Psychol Rev 2007; 114:113-51.

10. Grimm SD, Church TA, Katigbak MS, Reyes JAS. Self-described traits, values, and moods associated with individualism and collectivism testing I-C Theory in an individualistic (US) and a collectivistic (Philippine) culture. J Cross Cult Psychol 1999;30:466-500.

11. Realo A, Allik J, Vadi M. The hierarchal structure of collectivism. J Res Pers 1997;31:93-116.

12. Realo A, Koido K, Ceulemans E, Allik J. Three components of individualism. Eur J Personality 2002;16:163-84.

13. Wolfgang $A$, Josefowitz N. Chinese immigrant value changes with length of time in Canada and value differences compared to Canadian students. Can Ethn Stud 1978;2:130-5.

14. Raval VV, Martini TS, Raval PH. 'Would others think it is okay to express my feelings?' Regulation of anger, sadness and physical pain in Gujarati children in India. Social Dev 2007;16:79-105.

15. Roberts SJ, Bowyer J, Varghese S, Sawdon J. Infant crying patterns in Manali and London. Child Care Health Dev 1994;20:323-37.

16. Fogel A, Toda S, Masatoshi K. Mother-infant face-to-face interaction in Japan and the United States: A laboratory comparison using 3-month-old infants. Dev Psychol 1988;24:398-406.

17. Camras LA, Campos JJ, Bradshaw D, Oster H, Miyake K. Japanese and American infants' responses to arm restraint. Dev Psychol 1992;28:578-83.
18. Camras LA, Campos JJ, Campos R, et al. Production of emotional facial expressions in European American, Japanese, and Chinese infants. Dev Psychol 1998;34:616-28.

19. Garstein MA, Slobodskaya HR, Kinsht IA. Cross-cultural differences in temperament in the first year of life: United States of America (US) and Russia. Int J Behav Dev 2003;27:316-28.

20. Lewis M, Ramsay DS, Kawakami K. Differences between Japanese infants and Caucasian American infants in behavioural and cortisol response to inoculation. Child Dev 1993;64:1722-31.

21. Pillai Riddell RR, Stevens BJ, Cohen LL, Flora DB, Greenberg S. Predicting maternal and behavioural measures of infant pain: The relative contribution of maternal factors. Pain 2007;133:138-149.

22. Din L, Pillai Riddell RR, Gordner S. Brief report: Maternal emotional availability and infant pain-related distress. J Pediatr Psychol 2009;34:722-6.

23. Hofstede $G$, itim International. Geert Hofstede cultural dimensions. $<$ www.geert-hofstede.com > (Accessed on October 8, 2007).

24. Dayan J. Friendship bonds, perceived parental support and selfesteem in children from individualist and collectivist cultures. DAI: Sect B. Sci Eng 2000;60(7-B):3617. (Abst)

25. Sagy S, Orr E, Bar-On D. Individualism and collectivism in Israeli society: Comparing religious and secular high-school students. Hum Relat 1999;52:327-48.

26. Jahromi LB, Stifter CA, Putnam SO. Maternal regulation of infant reactivity from 2 to 6 months. Dev Psychol 2004;40:477-87.

27. Taddio A, Nulman I, Koren BS, Stevens B, Koren G. A revised measure of acute pain in infants. J Pain Symptom Manag 1995; 10:456-63.

28. Denny CS. The experience of being loved: Physical affection from parents as remembered from childhood. DAI: Sect B. Sci Eng 2006;68(2-B):1336. (Abst)

29. Power, TG, Kobayashi-Winata H, Kelley ML. Childrearing patterns in Japan and the United States: A cluster analysis. Int J Behav Dev 1992;15:185-205.

30. Caudill, WA, Schooler C. Child behavior and child rearing in Japan and the United States: An interim report. J Nerv Ment Dis 1973;157:323-38.

31. Rudy D, Grusec JE, Wolfe J. Implications of cross-cultural findings for a theory of family socialization. J Moral Educ 1999;28:299-310.

32. City of Toronto. Toronto's Racial Diversity. <www.toronto.ca/ toronto_facts/diversity.htm> (Accessed on August 2, 2010).

33. Ralston DA, Gustafson DJ, Elsass PM, Cheung F, Terpstra RH. Eastern values: A comparison of managers in the United States, Hong Kong, and the People's Republic of China. J Appl Psychol 1992;77:664-71.

34. Malpass RS, Poortinga YH. Strategies for design and analysis. In: Lonner WL, Berry JW, eds. Field Methods in Cross-Cultural Research. Beverly Hills: Sage, 1986:47-84.

35. Fouts HN, Roopnarine JL, Lamb ME. Social experiences and daily routines of African American infants in different socioeconomic contexts. J Fam Psychol 2007;21:655-64. 


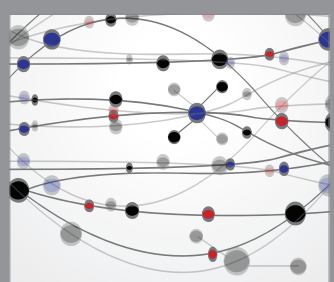

The Scientific World Journal
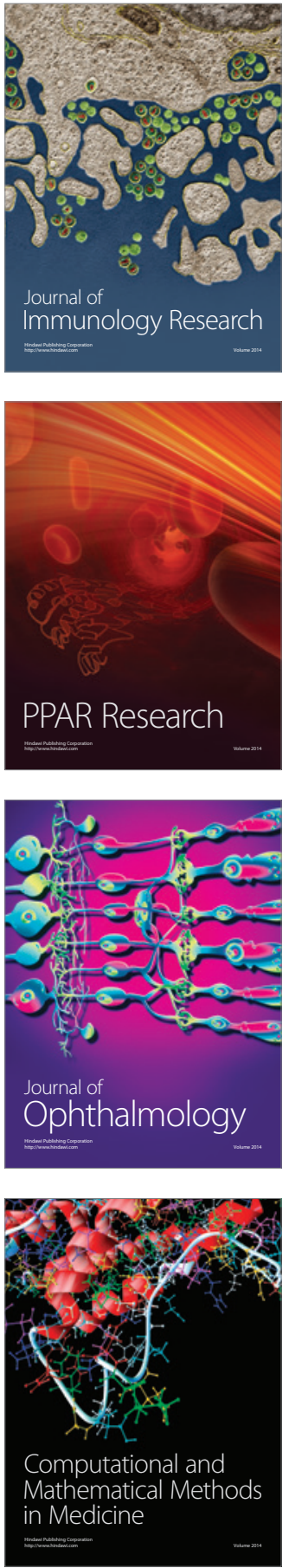

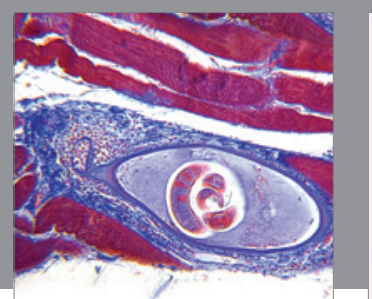

Gastroenterology Research and Practice

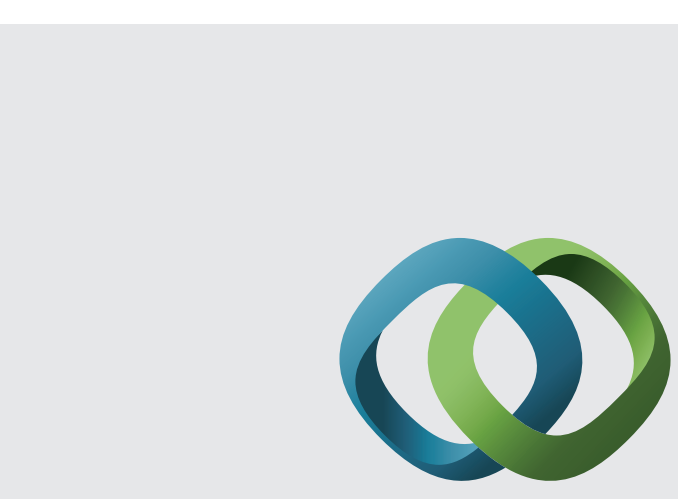

\section{Hindawi}

Submit your manuscripts at

http://www.hindawi.com
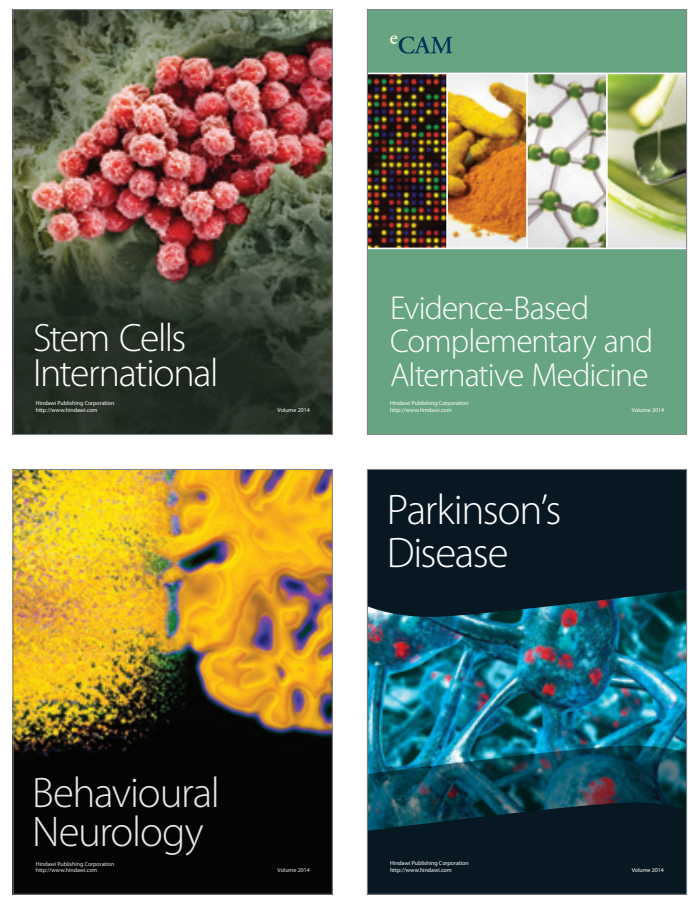
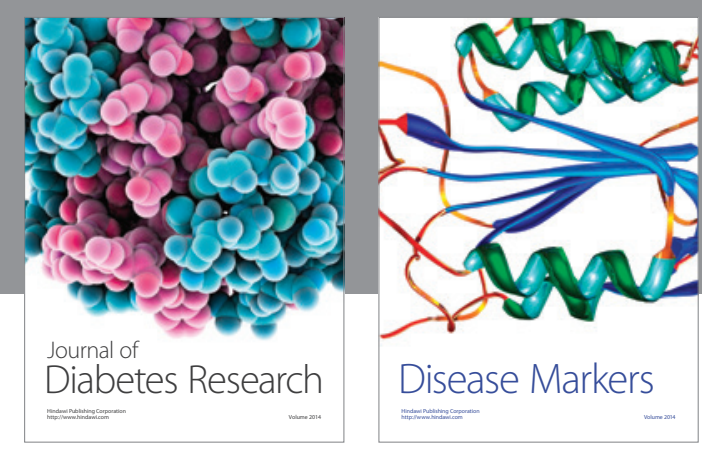

Disease Markers
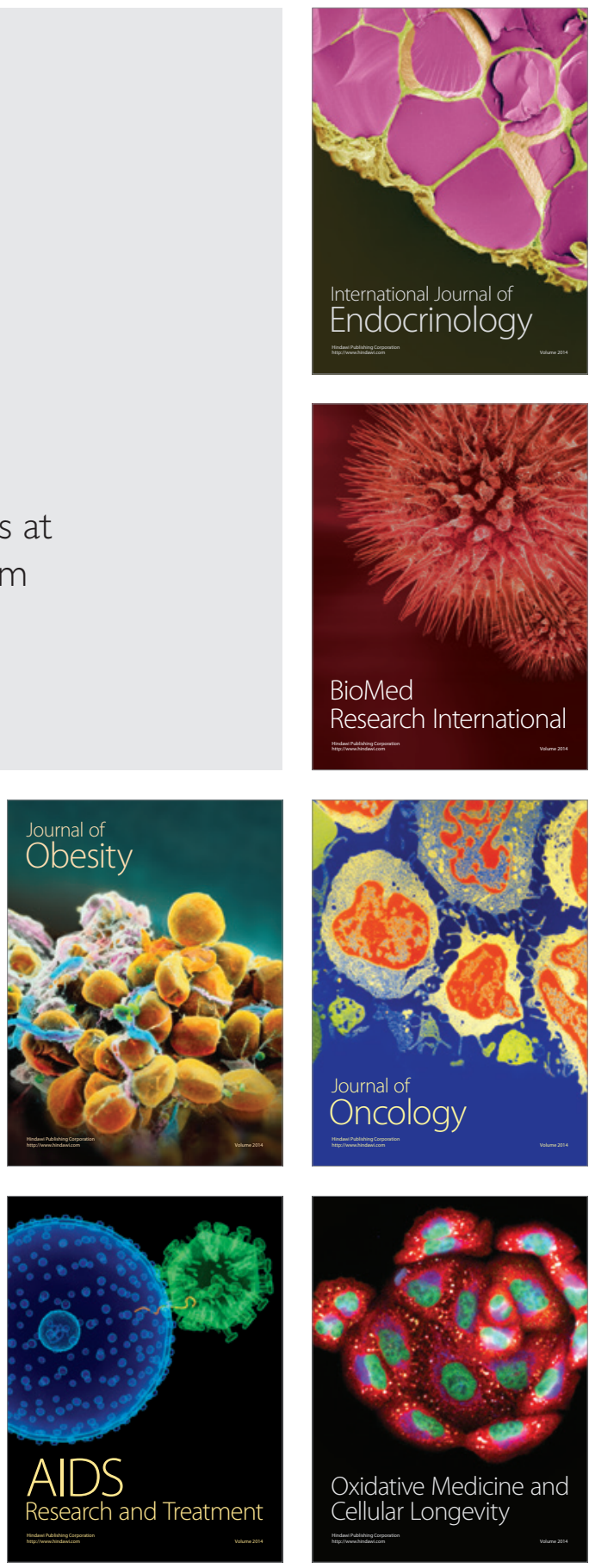